\title{
Effect of operating conditions and TWC parameters on emissions characteristics of a China-VI stoichiometric natural gas engine
}

\author{
Yedi Ren ${ }^{1}$, Diming Lou ${ }^{1}$, Xiang Li ${ }^{1}$, Yunhua Zhang ${ }^{1, *}$, and Xia Sun ${ }^{2}$ \\ 1 School of Automotive studies, Tongji University, Shanghai 201804, China \\ ${ }^{2}$ China National Heavy Duty Truck Group Co., Ltd, Jinan 250101, China
}

\begin{abstract}
This study involved conducting an experimental and numerical investigation on the effects of the air-to-fuel ratio (AFR), engine speed, and engine load on the inlet gas component of a three-way catalyst (TWC) and on the effects of noble metal loading, noble metal ratio, and carrier pore density on the emission conversion efficiency. The results showed that AFR can significantly affect the raw emissions of NOx and THC, and better emission conversion efficiency of a TWC can be reached when AFR is controlled between 0.995 to 1 . Compared with engine speed, engine load has a relatively small effect on exhaust temperature but greatly affects the flow velocity and NOx and THC emissions. Increasing the content of Pt in the catalyst can improve the THC conversion efficiency. For low Pt and Pd-Rh catalysts, the THC conversion effect is significantly deteriorated. The content of Rh affects the NOx conversion, and NOx conversion efficiency at high speeds is significantly reduced when Rh content is reduced. Higher carrier pore density can slightly improve the catalytic reaction rate and emission conversion efficiency at high engine speeds. However, high conversion efficiency can be maintained even after aging.
\end{abstract}

\section{Introduction}

Due to stringent emissions regulations and the high cost of diesel fuel, alternative fuels provide solutions to an array of environmental and economic problems. Among alternative gaseous fuels, natural gas is regarded as the most promising for internal combustion engine [1-4]. Compared with gasoline, natural gas (NG) shows many advantages as motor fuel. A higher octane number leads to a lower tendency to knock and makes it easier to achieve a higher compression ratio and, therefore, better thermal efficiency. In terms of safety, natural gas is volatile, and it has a higher spontaneous combustion temperature and flammable limit. In addition, natural gas has a lower carbon content, and as motor fuel, its $\mathrm{CO}_{2}$ emissions are lower compared with gasoline and diesel [5-6].

\footnotetext{
*Corresponding author: zhangyunhua313@163.com
} 
Lean-burn operation and stoichiometric operation are the two main routes of spark ignition (SI) in natural gas engines. Before the implementation of Euro-VI emission standards on heavy-duty engines, lean-burn mode was commonly applied to NG SI engines due to its lower knock tendency and better thermal efficiency [7,8]. In order to meet the stringent emissions requirements of non-methane total hydrocarbons (NMHC), $\mathrm{CH}_{4}$ and nitrogen oxides (NOx) in the latest emission standard, heavy-duty NG SI engines are designed to operate on a stoichiometric mixture combined with a three-way catalyst (TWC) and an ammonia slip catalyst (ASC). This mode is generally recognized as the most effective for $\mathrm{NG}$ engines due to its very low emissions and after-treatment costs compared with lean burn operation [9-11].

Currently, the TWC catalyst typically has a dual-layer washcoat applied to a cordierite substrate. In general, the underlayer is alumina rich, and the top layer contains oxygen storage (OSC) components, mainly Ce-Zr-mixed oxides. Both layers contain dispersed platinum group metal (PGM) components [12, 13]. Ce-Zr-mixed oxides, are added to the TWC formulation to buffer the perturbations near the stoichiometric operation of engines. Zirconium oxide itself have no OSC, but its incorporation with cerium oxides can improve the thermal stability and enhance the oxygen transport under lean/rich gas cycling reaction conditions [14]. At first, TWC formulation for natural gas engines was mainly referred to gasoline engines [15]. The active components were mainly platinum (Pt), a small amount of rhodium (Rh) and $\mathrm{CeO}_{2}$ as a performance additive[16]. However, 90\% to $95 \%$ of hydrocarbon emissions in the exhaust gas of natural gas engines are $\mathrm{CH}_{4} . \mathrm{CH}_{4}$ is difficult to oxidize catalytically, and the exhaust gas also contains a large amount of water vapor and a small amount of $\mathrm{SO}_{2}$. Using gasoline formulation may reduce $\mathrm{CH}_{4}$ conversion efficiency to less than $15 \%$ and cause poisoning and catalyst deactivation. Therefore, a TWC for gasoline vehicles is not suitable for the purification of natural gas engines [17,18]. Other than the catalyst and carrier, the catalytic performance of a TWC is also affected by operating conditions, such as the air-to-fuel ratio (AFR), engine speed, and engine load. The TWC efficient working window of natural gas engines is narrower than that of gasoline engines. When AFR is controlled toward the lean-burn side, the conversion efficiency of hydrocarbons and NOx decreases rapidly [19]. Moreover, noble metal composition can influence the conversion efficiency of emissions, which is caused by complicated coherent effects or synergistic effects among different noble metals and additive.

Therefore, research on TWCs is particularly important for natural gas engines using stoichiometric operation. Some research on the performance of TWCs for natural gas engines has been conducted, but most studies carried out sample tests, so there are still few studies based on engine tests. Huo et al. [20] studied the effect of the noble metal ratio on the catalytic performance of natural gas engines on a sample test bench and found that a certain percentage of $\mathrm{Pt}$ had a promoting effect on $\mathrm{CH}_{4}$ and NOx conversion efficiency but basically no effect on $\mathrm{CO}$ conversion efficiency. Zhang et al. [21] used $\mathrm{Pd}$ and a small amount of Pt as components to conduct comparative analysis through a sample test. The results showed that $\mathrm{Al}_{2} \mathrm{O}_{3} / \mathrm{SiO}_{2}$ as a coating material has good anti-sulfur poisoning ability and catalytic performance. $\mathrm{Xi}$ et al. [22] found that because of the reliance of NOx conversion on $\mathrm{CO}$ and $\mathrm{H}_{2}, \mathrm{CH}_{4}$ conversion can strongly affect $\mathrm{NOx}$ conversion. Hajbabaei et al. [4] found that the stoichiometric engine significantly reduced NOx and THC emissions compared to the leanburn engine but also resulted in higher levels of $\mathrm{CO}$ and ammonia $\left(\mathrm{NH}_{3}\right)$ emissions. Takayuki [23] and $\mathrm{Oh}$ [24] investigated the effect of noble metals in the catalyst on emissions, finding that $\mathrm{Pd}$ had the best effect on the conversion of $\mathrm{CH}_{4}$, whereas $\mathrm{Pt}$ and $\mathrm{Rh}$ were less effective. The high-efficiency working window of Pd is narrow, and when AFR increases, the conversion efficiency of $\mathrm{CH}_{4}$ decreases significantly. Some numerical study on TWC models have also been carried out. Maio et al. [25] investigate the effect of very fast composition transitions of the engine exhaust typical in real-world driving operating conditions. A 
predictive model of catalyst behaviour with oxygen storage and release of a heavy-duty engine powered with NG was developed. Zeng et al. [26] establish a kinetic model of threeway catalyst and found that lower exhaust emission on a natural gas engine with a TWC can be achieved with an optimal dithering amplitude of AFR.

In order to determine the effect of the engine operation condition on the inlet state of a TWC and the effect of the TWC parameter on the conversion efficiency of main emissions, a bench test and numerical simulation were conducted in this study. This paper aims to reveal the effects of AFR, engine speed, and engine load on the inlet gas component of TWCs as well as the effects of noble metal loading, noble metal ratio and carrier pore density on the conversion efficiency of NOx and THC to provide TWC optimization guidelines for natural gas engines.

\section{Experimental setup and simulation}

\subsection{Test platform and experimental apparatus}

A six-cylinder, 12.42-liter turbocharged NG SI engine with a compression ratio of 11.46:1 was used for this experimental study. The specifications of the tested engine are shown in Table 1. A continuous-flow valve was employed for precise fuel supply control. The AFR was controlled by a closed-loop control system with a broadband oxygen sensor, and AFR was controlled by default at 0.995 . The schematic of the experimental device is illustrated in Fig. 1.

Table 1. Specifications of tested engine.

\begin{tabular}{|c|c|}
\hline Parameter & Value \\
\hline Engine type & In-line six-cylinder \\
\hline Displacement $(\mathrm{L})$ & 12.419 \\
\hline Bore $(\mathrm{mm})$ & 126 \\
\hline Stoke $(\mathrm{mm})$ & 166 \\
\hline Compression ratio & $11.46: 1$ \\
\hline Intake mode & Turbocharged, intercooler \\
\hline Fuel type & Natural gas \\
\hline Mixture formation & Continuous flow valve system \\
\hline Ignition mode & High energy spark ignition \\
\hline Combustion chamber & Flat head, bowl piston \\
\hline Maximum torque $(\mathrm{N} \cdot \mathrm{m}) /$ Speed $(\mathrm{r} / \mathrm{min})$ & $2100 / 1300$ \\
\hline Rated power $(\mathrm{kW}) /$ Speed $(\mathrm{r} / \mathrm{min})$ & $330 / 1800$ \\
\hline
\end{tabular}

A high-pressure loop external exhaust gas re-circulation (EGR) system was implemented, which consisted of an EGR cooler, a one-way valve and a cold-side EGR valve. The EGR rate is defined by Eq. (1):

$$
\mathrm{EGR} \text { rate }=\frac{\mathrm{CO}_{2-\text { inlet }}}{\mathrm{CO}_{2-\text { outlet }}} * 100 \%,
$$

where $\mathrm{CO}_{2 \text {-inlet }}$ and $\mathrm{CO}_{2-\text { outlet }}$ are the volumetric concentrations of carbon dioxide $(\mathrm{CO} 2)$ in the intake and exhaust system, respectively.

The composition of natural gas has a significant impact on engine combustion. The natural gas used in the test had a high methane content, and the main properties of the fuel at $20^{\circ} \mathrm{C}$ and 1 standard atmosphere (atm) are shown in Table 2. 
Table 2. The main compositions and properties of natural gas used in the test.

\begin{tabular}{|c|c|c|c|}
\hline \multicolumn{2}{|c|}{$\begin{array}{c}\text { Compositions } \\
\text { (vol\%) }\end{array}$} & \multicolumn{2}{c|}{ Property } \\
\hline $\mathrm{CH}_{4}$ & 99.28 & Higher heating value $(\mathrm{MJ} / \mathrm{kg})$ & 55.34 \\
\hline $\mathrm{C}_{2} \mathrm{H}_{6}$ & 0.42 & Lower heating value $(\mathrm{MJ} / \mathrm{kg})$ & 49.86 \\
\hline $\mathrm{C}_{3} \mathrm{H}_{8}$ & 0.10 & Molecular weight $(\mathrm{g} / \mathrm{mol})$ & 16.17 \\
\hline $\mathrm{iC}_{4} \mathrm{H}_{10}$ & 0.02 & Density $\left(\mathrm{kg} / \mathrm{m}^{3}\right)$ & 0.6733 \\
\hline $\mathrm{nC}_{4} \mathrm{H}_{10}$ & 0.02 & & \\
\hline
\end{tabular}

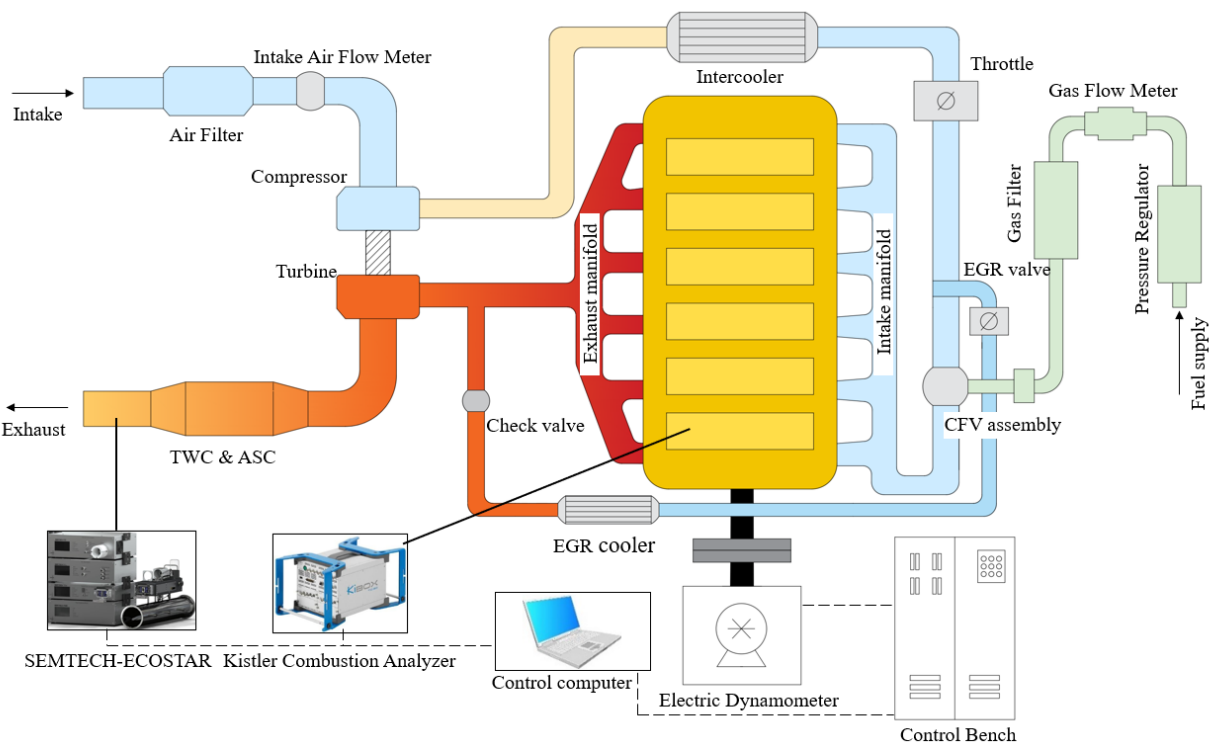

Fig. 1. The schematic diagram of experimental setup and engine test bench.

To obtain the emission state of the engine, a SEMTECH-D emissions test system (Sensors, Inc., USA) was used to detect THC, NOx, and $\mathrm{CO}$ concentration in the exhaust gas. The SEMTECH-FID module uses a heated flame ionization detector (HFID) to measure the total hydrocarbon concentration; its detection range is $0-3000 \mathrm{ppmc}$, and its resolution is $1 \mathrm{ppm}$. The SEMTECH-NOx module directly measures $\mathrm{NO}$ and $\mathrm{NO}_{2}$ concentration through nondispersive ultraviolet (NDUV) to obtain the NOx concentration value with a resolution of 0.3 ppm. Finally, the SEMTECH-FEM module uses non-dispersive infrared (NDIR) technology to measure the $\mathrm{CO}$ and $\mathrm{CO}_{2}$ concentrations.

This study investigated the effect of operating conditions on TWC inlet parameters and the influence of TWC parameters on catalytic performance of natural gas engine exhaust. The test conditions were controlled by the test bench, and the electronic throttle, excess air ratio, and EGR rate were controlled using electronic control unit (ECU) software. Before each test, the engine was fully warmed and the backpressure of the engine was adjusted to $1.35 \mathrm{MPa}$ with $100 \%$ load at $1800 \mathrm{r} / \mathrm{min}$. An inlet air conditioning system was used to maintain the temperature, humidity, and pressure of the inlet air at $20 \pm 2{ }^{\circ} \mathrm{C}, 45 \pm 3 \%$, and $101 \pm 1 \mathrm{kPa}$, respectively. During the test, the outlet cooling temperature of the intercooler was controlled by PID and the control target was set to $90^{\circ} \mathrm{C}$.

To access the effects of AFR, engine speed, and engine load on the inlet state of TWCs, engine emission test operating points were designed as shown in Fig. 2. The engine was allowed to maintain a steady state for 2 minutes before emissions were sampled and data were collected. 
To reduce the cost of TWCs, seven sets of TWCs with different parameters were designed and manufactured based on the mainstream TWC design parameters. The size of the TWC was $152.4 \mathrm{~mm}$ (length) $\times 304.8$ (diameter). Additionally, all tested TWCs were tightly coupled with an ammonia slip catalyst (ASC); the size was $76.2 \mathrm{~mm}$ (length) $\times 304.8 \mathrm{~mm}$ (diameter), and it contained $10 \mathrm{~g} / \mathrm{ft}^{3} \mathrm{Pt}$. The test intentions and specific design parameters of the seven sets of TWCs are shown in Table 3.

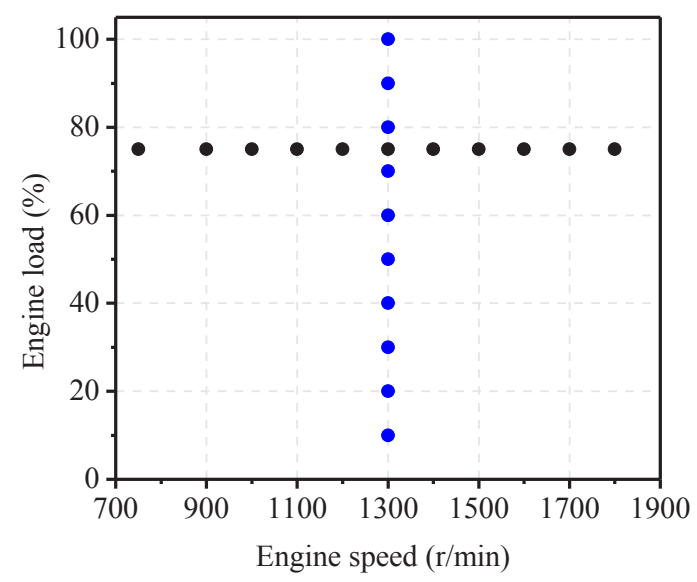

Fig. 2. The tested operating conditions.

Table 3. The parameters of tested three-way catalysts.

\begin{tabular}{|c|c|c|c|}
\hline Case & $\begin{array}{c}\text { Pore density } \\
\text { (cpsi) }\end{array}$ & $\begin{array}{c}\text { Noble metal } \\
\text { loading }\left(\mathrm{g} / \mathrm{ft}^{3}\right)\end{array}$ & $\begin{array}{c}\text { Noble metal ratio } \\
\text { (Pt:Pd:Rh) }\end{array}$ \\
\hline TWC1 & 400 & 150 & $45 / 100 / 15$ \\
\hline TWC2 & 400 & 120 & $45 / 100 / 15$ \\
\hline TWC3 & 400 & 100 & $45 / 100 / 15$ \\
\hline TWC4 & 400 & 150 & $30 / 100 / 10$ \\
\hline TWC5 & 400 & 150 & $55 / 85 / 10$ \\
\hline TWC6 & 400 & 150 & $0 / 140 / 10$ \\
\hline TWC7 & 600 & 150 & $45 / 100 / 15$ \\
\hline
\end{tabular}

\subsection{Numerical simulation of three-way catalysts}

In order to study the effect of engine control parameters and TWC parameters on catalytic conversion efficiency, a numerical model of the catalyst was established, including a catalytic reaction kinetics model, heat and mass transfer model, and control equations.

For the traditional TWC used on gasoline vehicles, Koltsakis [27] proposed a fivereaction mechanism based on the existing research. The exhaust components of natural gas engines are different from traditional gasoline engines, and also the catalyst is different. Therefore, the reaction mechanism of traditional TWCs is not applicable to natural gas engines. Considering that the main part of hydrocarbon emissions of natural gas engine is $\mathrm{CH}_{4}$, the traditional five-reaction mechanism is adjusted, and the following reaction mechanism is established:

$$
\begin{array}{cc}
\mathrm{CO}+\frac{1}{2} \mathrm{O}_{2} \rightarrow \mathrm{CO}_{2} & , Q_{R}=-2.83 \times 10^{5} \mathrm{~J} / \mathrm{mol} \\
\mathrm{CH}_{4}+2 \mathrm{O}_{2} \stackrel{\mathrm{CO}_{2}+2 \mathrm{H}_{2} \mathrm{O}}{\rightarrow}, Q_{R}=-8.02 \times 10^{5} \mathrm{~J} / \mathrm{mol}
\end{array}
$$




$$
\begin{array}{rr}
\mathrm{C}_{3} \mathrm{H}_{6}+\frac{9}{2} \mathrm{O}_{2} \rightarrow 3 \mathrm{CO}_{2}+3 \mathrm{H}_{2} \mathrm{O}, Q_{R}=-1.93 \times 10^{6} \mathrm{~J} / \mathrm{mol} \\
\mathrm{H}_{2}+\frac{1}{2} \mathrm{O}_{2} \rightarrow \mathrm{H}_{2} \mathrm{O} & , Q_{R}=-2.42 \times 10^{5} \mathrm{~J} / \mathrm{mol} \\
\mathrm{CO}+\mathrm{NO} \rightarrow \mathrm{CO}_{2}+\frac{1}{2} \mathrm{~N}_{2} & , Q_{R}=-3.73 \times 10^{5} \mathrm{~J} / \mathrm{mol} \\
\mathrm{CH}_{4}+\mathrm{H}_{2} \mathrm{O} \rightarrow \mathrm{CO}+3 \mathrm{H}_{2} & , Q_{R}=+2.06 \times 10^{5} \mathrm{~J} / \mathrm{mol} \\
\mathrm{C}_{3} \mathrm{H}_{6}+3 \mathrm{H}_{2} \mathrm{O} \rightarrow 3 \mathrm{CO}+6 \mathrm{H}_{2} & , Q_{R}=+3.74 \times 10^{5} \mathrm{~J} / \mathrm{mol}
\end{array}
$$

where $\mathrm{QR}$ is the heat of the chemical reaction, and its value is positive for endothermic reactions and negative for exothermic reactions.

The main component of the fuel used in the bench test was $\mathrm{CH}_{4}$, which accounted for more than $99 \%$,as shown in Table 2 . To simplify the numerical model, only the oxidation and steam reforming reactions of $\mathrm{CH}_{4}$ were considered, and other alkanes were ignored. Besides, the following assumptions were made: the gas flow state in each channel is consistent; there is neither heat nor mass transfer between the carriers; the geometric shape and the active components coated on the surface are the same; the inlet gas parameters (i.e., flow rate, temperature, composition) are consistent; the gas flow in is a fully developed laminar flow; the heat and mass transfer of the gas flow in the carrier channel in the axial direction is ignored; the inlet gas is an ideal gas with an average molecular weight, and there is no mutual reaction between the components.

For heat and mass exchange at the gas-solid boundary, the lumped parameter model was used, and the convective heat-transfer coefficient and convective mass-transfer coefficient were calculated using the dimensionless Nusselt number and the Sherwood number. In this paper, the Nusselt and Sherwood numbers were corrected by the bench test result and calculated by Eqs. (9) and (10):

$$
\begin{gathered}
N u=1.86\left(\operatorname{Re} \cdot \operatorname{Pr} \cdot \frac{d_{h}}{L_{d}}\right)^{1 / 3} \\
S h=1.86\left(\operatorname{Re} \cdot S c \cdot \frac{d_{h}}{L_{d}}\right)^{1 / 3}
\end{gathered}
$$

According to the parameters of the carrier and the physical properties of the material, combined with the actual test environment conditions, the model parameters for numerical calculation were determined, as shown in Table 4.

Table 4. Parameters used in the numerical model.

\begin{tabular}{|c|c|c|c|}
\hline Parameter & Value & Parameter & Value \\
\hline$\rho_{g} / \mathrm{kg} / \mathrm{m}^{3}$ & 0.409 & $\rho_{s} / \mathrm{kg} / \mathrm{m} 3$ & 2.5 \\
\hline$\lambda_{g} / \mathrm{J} /(\mathrm{m} \cdot \mathrm{s} \cdot \mathrm{K})$ & 0.062 & $\lambda_{s} / \mathrm{J} /(\mathrm{m} \cdot \mathrm{s} \cdot \mathrm{K})$ & 2.0 \\
\hline$C_{P g} / \mathrm{J} /(\mathrm{kg} \cdot \mathrm{K})$ & $1.11 \times 103$ & $C_{P S} / \mathrm{J} /(\mathrm{kg} \cdot \mathrm{K})$ & $1.0 \times 103$ \\
\hline$T_{\infty} / \mathrm{K}$ & 300 & $v_{g} / \mathrm{m} / \mathrm{s}$ & 10.3 \\
\hline $\mathrm{Nu}$ & 3.66 & $\varepsilon$ & 0.85 \\
\hline $\mathrm{Ga} / \mathrm{m}^{2} / \mathrm{m}^{3}$ & 2900 & $D_{h} / \mathrm{mm}$ & 1.17 \\
\hline
\end{tabular}

Based on the test results, the parameters of the oxidation reaction mechanism and the reduction reaction mechanism were calibrated separately to determine the activation energy and pre-finger factor of the reaction. The constructed chemical reaction mechanism is shown in Table 5, where the unit of the pre-factor is related to the reaction order, and the unit of activation energy of the chemical reaction is $\mathrm{kJ} / \mathrm{mol}$. 
Table 5. Catalytic reaction mechanism used in simulation.

\begin{tabular}{|c|c|c|}
\hline Chemical reaction & $\begin{array}{c}\text { Pre- } \\
\text { exponential } \\
\text { factor }\end{array}$ & $\begin{array}{c}\text { Activation } \\
\text { energies } \\
\text { (kJ/mol) }\end{array}$ \\
\hline $\mathrm{CO}+1 / 2 \mathrm{O}_{2}=>\mathrm{CO}_{2}$ & $1.69 \mathrm{E}+15$ & 91450 \\
\hline $\mathrm{CH}_{4}+2 \mathrm{O}_{2}=>\mathrm{CO}_{2}+2 \mathrm{H}_{2} \mathrm{O}$ & $5.12 \mathrm{E}+15$ & 85600 \\
\hline $\mathrm{H}_{2}+1 / 2 \mathrm{O}_{2}=>\mathrm{H}_{2} \mathrm{O}$ & $3.79 \mathrm{E}+12$ & 21200 \\
\hline $\mathrm{CO}+\mathrm{NO}=>\mathrm{CO}_{2}+1 / 2 \mathrm{~N}_{2}$ & $1.61 \mathrm{E}+15$ & 52400 \\
\hline $\mathrm{CH}_{4}+\mathrm{H}_{2} \mathrm{O}=>\mathrm{CO}+3 \mathrm{H}_{2}$ & $4.90 \mathrm{E}+12$ & 128000 \\
\hline
\end{tabular}

The conversion efficiency obtained by numerical simulation is in the form of a solid curve, and the bench test results are expressed in the form of scattered points, as shown in Fig. 3. It can be seen that the simulation results are basically consistent with the test results, and the deviation value is less than $2 \%$ in the common AFR range of the engine, which can meet the simulation needs.

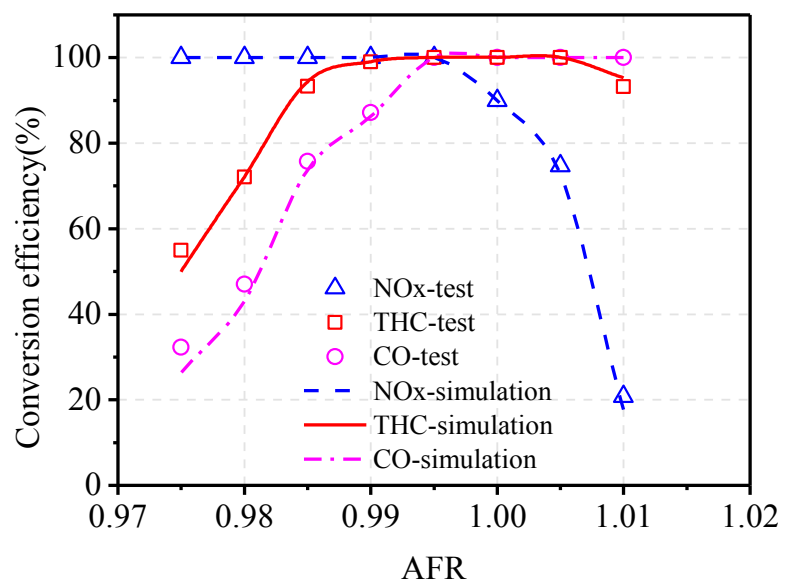

Fig. 3. Comparison of simulation results and test results of catalytic conversion efficiency.

\section{Results and discussion}

\subsection{Analysis of results under different operation conditions}

\subsubsection{Effect of air-to-fuel ratio}

The inlet component of a TWC greatly affects the catalytic efficiency, and the inlet component of a TWC is determined by the engine operating conditions and control parameters. To analyse the effect of AFR on raw emissions of the engine and conversion efficiency of a TWC, steady-state tests were conducted at two operating conditions: 2100 $\mathrm{N} \cdot \mathrm{m}$ at $1300 \mathrm{r} / \mathrm{min}$ (full-load condition at maximum torque speed) and $1700 \mathrm{~N} \cdot \mathrm{m}$ at 1800 $\mathrm{r} / \mathrm{min}$ (full-load condition at maximum power speed), which are the most important operating conditions for engine calibrations. EGR rate was controlled at $17.5 \%$.

Fig. 4 and 5 show the effect of AFR on raw emissions of the engine and conversion efficiency of a TWC under the condition of $2100 \mathrm{~N} \cdot \mathrm{m}$ at $1300 \mathrm{r} / \mathrm{min}$. As shown in Fig. 4(a), raw NOx emissions of the engine continuously increased with the increase of AFR from 
0.975 to 1.02 . Although the change of AFR slightly affected the combustion temperature and duration of high temperature, the increase of NOx emissions was mainly caused by increasing oxygen concentration. The increase of AFR led to a significant drop in raw $\mathrm{CO}$ emissions but showed little effect on raw THC emissions. As can be seen in Fig. 4(b), the trends of raw NOx, THC, and CO emissions at $1800 \mathrm{r} / \mathrm{min}$ were basically the same as those at $1300 \mathrm{r} / \mathrm{min}$. NOx emissions were relatively lower due to higher EGR rate and shorter high-temperature duration compared to that of $1300 \mathrm{r} / \mathrm{min}$. THC and $\mathrm{CO}$ emissions increased when the engine speed increased from $1300 \mathrm{r} / \mathrm{min}$ to $1800 \mathrm{r} / \mathrm{min}$. This was mainly due to the increase of unburnt fuel caused by wall and bulk quenching as well as leaking during valve overlapping [28].
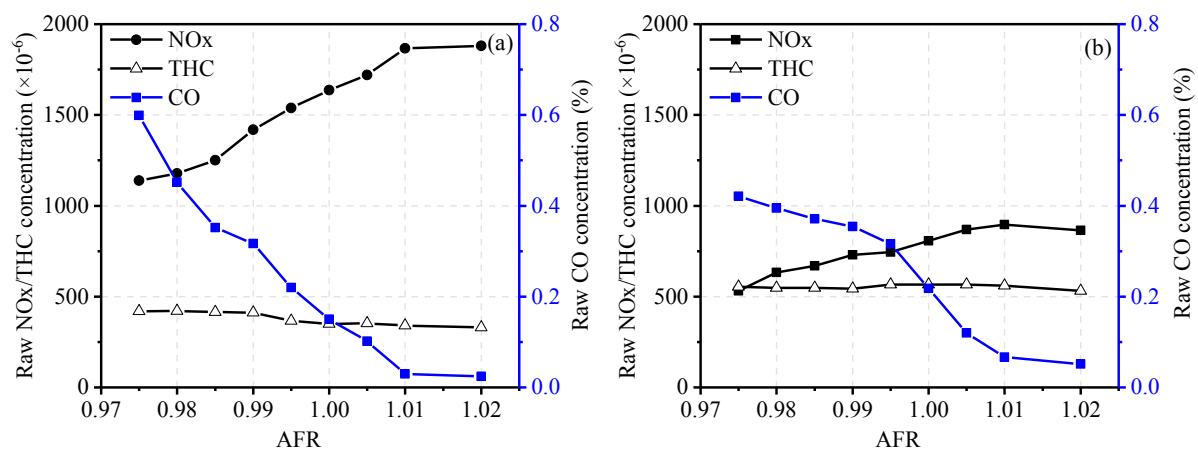

Fig. 4. Raw emissions of the engine under the conditions of (a) $2100 \mathrm{~N} \cdot \mathrm{m}$ at $1300 \mathrm{r} / \mathrm{min}$ and (b) $1700 \mathrm{~N} \cdot \mathrm{m}$ at $1800 \mathrm{r} / \mathrm{min}$.

As illustrated in Fig. 5(a), the conversion efficiencies of $\mathrm{CO}$ and THC were quite low when AFR $<0.99$ due to the lack of $\mathrm{O}_{2}$ in the exhaust gas. As NOx emissions were lower and the reductant was sufficient due to higher $\mathrm{CO}$ and $\mathrm{THC}$ emissions, the conversion efficiency of NOx was quite high, staying at more than 99\%. As shown in Fig. 5(b), the conversion efficiency of $\mathrm{CO}$ was lower when AFR $<0.99$, which was caused by lower NOx emissions at $1800 \mathrm{r} / \mathrm{min}$. When AFR increased from 0.99 to 1.00 , the conversion efficiencies of $\mathrm{CO}$ and THC rapidly increased, and the efficiency of NOx started to decrease. When AFR > 1.00 , the conversion efficiency of CO stayed at about $100 \%$, but the efficiency of THC decreased eventually, which was due to the oxidation activity of $\mathrm{CH}_{4}$ being significantly reduced when AFR was controlled at the lean side.
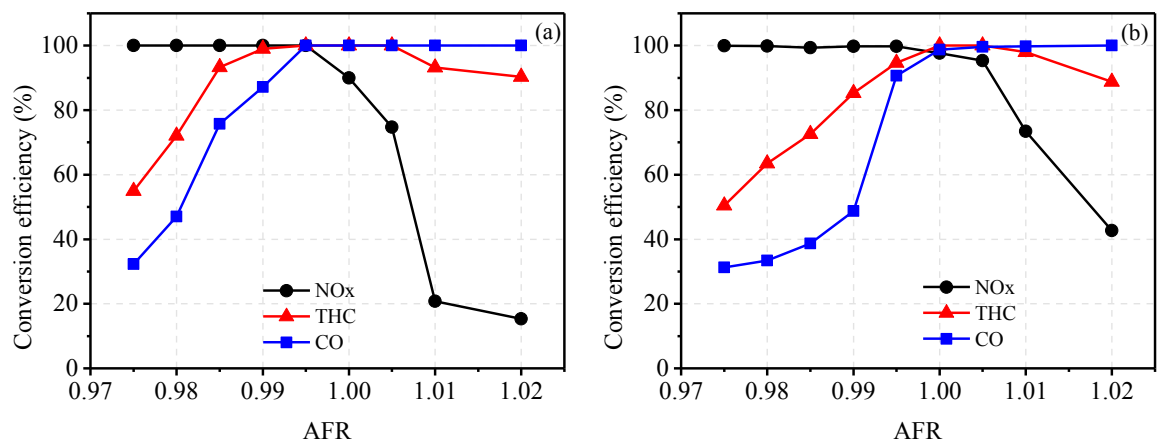

Fig. 5. Conversion efficiency of emissions under the conditions of (a) $2100 \mathrm{~N} \cdot \mathrm{m}$ at $1300 \mathrm{r} / \mathrm{min}$ and (b) $1700 \mathrm{~N} \cdot \mathrm{m}$ at $1800 \mathrm{r} / \mathrm{min}$. 


\subsubsection{Effect of engine speed}

To clarify the effects of engine speed on the inlet gas state of TWCs, the EGR rate was kept constant at $17.5 \%$, and the engine load was maintained at $75 \%$ load. Fig. 6 and Fig. 7 show the effects of engine speed on raw emissions, exhaust temperature, and flow velocity.

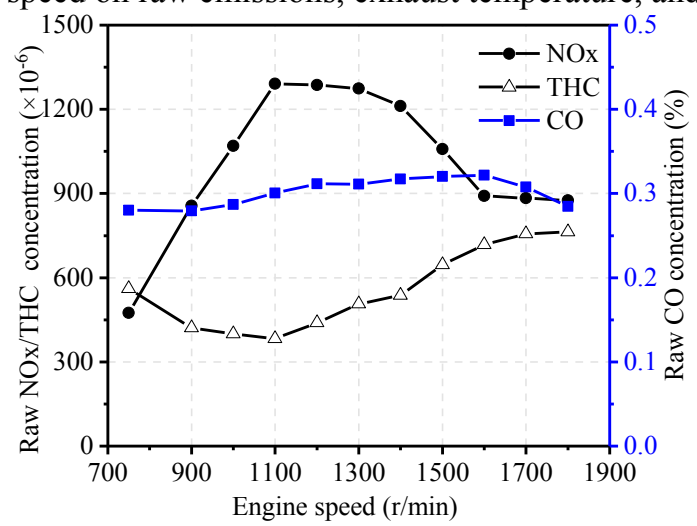

Fig. 6. Effect of engine speed on exhaust components.

As shown in Fig. 6, with the increase of engine speed, NOx emissions rapidly increased, reached a peak value near $1100 \mathrm{r} / \mathrm{min}$ and then started to decrease. The CO concentration showed little change with the increase of engine speed, whereas THC emissions decreased before eventually beginning to increase when the engine speed was more than $1100 \mathrm{r} / \mathrm{min}$. As illustrated in Fig. 7, with the increase of engine speed, the exhaust temperature increased almost linearly from $510^{\circ} \mathrm{C}$ at $750 \mathrm{r} / \mathrm{min}$ to $590^{\circ} \mathrm{C}$ at $1800 \mathrm{r} / \mathrm{min}$. However, the exhaust flow velocity through the catalyst carrier increased significantly, and the rate of increase slowed down slightly at high engine speeds.

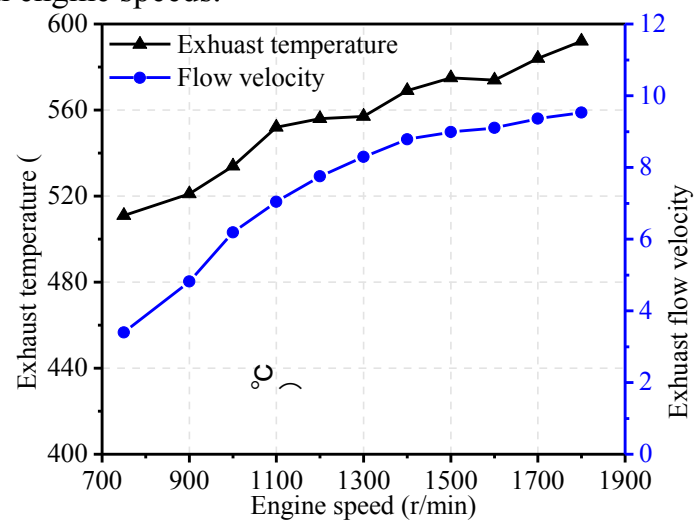

Fig. 7. Effect of engine speed on exhaust temperature and flow velocity.

\subsubsection{Effect of engine load}

To evaluate the effects of engine load on the inlet gas state of TWCs, the EGR rate was kept constant at $17.5 \%$, and the engine load was maintained at $1300 \mathrm{r} / \mathrm{min}$. Figs. 8 and 9 illustrate the effects of engine load on raw emissions, exhaust temperature, and flow velocity. As shown in Fig. 8, the raw NOx concentration monotonously increased with the increase of engine load at $1300 \mathrm{r} / \mathrm{min}$. Under low load conditions, the NOx concentration was low due to the low in-cylinder temperature. With the increase of engine load, NOx emissions 
gradually increased until they became stable at high load. Similar to the trend in the test of engine speed, the $\mathrm{CO}$ concentration showed only slight changes with the change of engine load, staying at about $0.3 \%$. THC emissions initially increased before eventually dropping down, and the maximum value was reached at about $30 \%$ load.

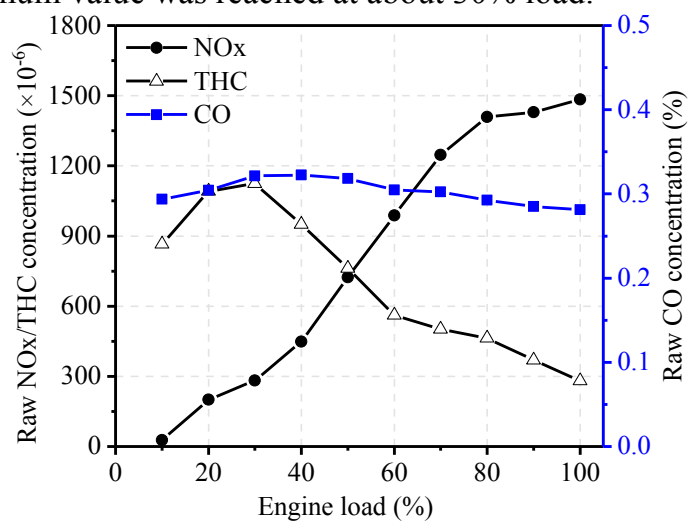

Fig. 8. Effect of engine load on exhaust components.

With the increase of engine load, the flow velocity increased almost linearly as shown in Fig. 9. The exhaust temperature varied greatly at high load and low load but remained basically unchanged at medium load.

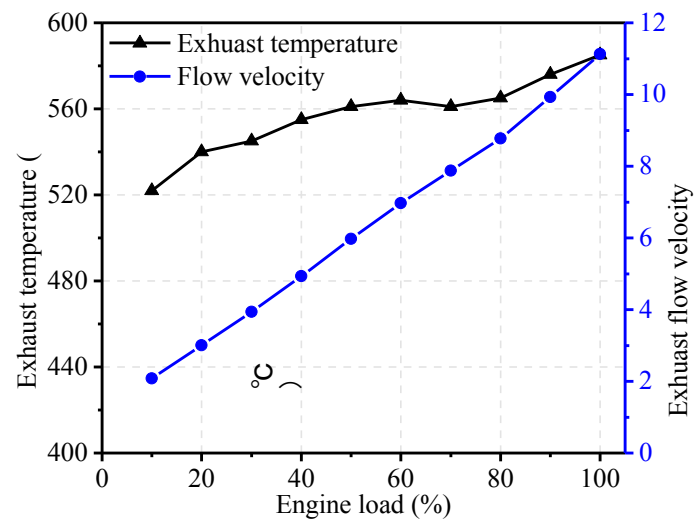

Fig. 9. Effect of engine load on exhaust temperature and flow velocity.

\subsection{Analysis of results of emissions using different three-way catalysts}

\subsubsection{Effect of noble metal loading}

To access the effect of noble metal loading on the performance of TWCs, emission tests were conducted on the natural gas engine matching with three different TWCs. The noble metal loading was $150 \mathrm{~g} / \mathrm{ft}^{3}$ for $1 \#$ TWC, $120 \mathrm{~g} / \mathrm{ft}^{3}$ for $2 \#$ TWC and $100 \mathrm{~g} / \mathrm{ft}^{3}$ for $3 \#$ TWC, as mentioned in Table 3.

Fig. 10 shows the effect of noble metal loading on the NOx conversion efficiency of TWCs at $75 \%$ engine load from $750 \mathrm{r} / \mathrm{min}$ to $1800 \mathrm{r} / \mathrm{min}$. As the engine speed increased, the conversion efficiency of NOx started to decrease when the engine speed was higher than $1300 \mathrm{r} / \mathrm{min}$. At high engine speeds, the higher flow velocity through the carrier led to the shorter residence time of exhaust gas in the catalyst, which reduced the NOx conversion 
efficiency. Comparing three TWCs with different noble metal loading, it can be seen that $3 \#$ TWC showed relatively lower conversion efficiency at high engine speeds (about $1 \%$ lower). At low and medium engine speeds, noble metal loading seemed to have little effect on the conversion efficiency of NOx.

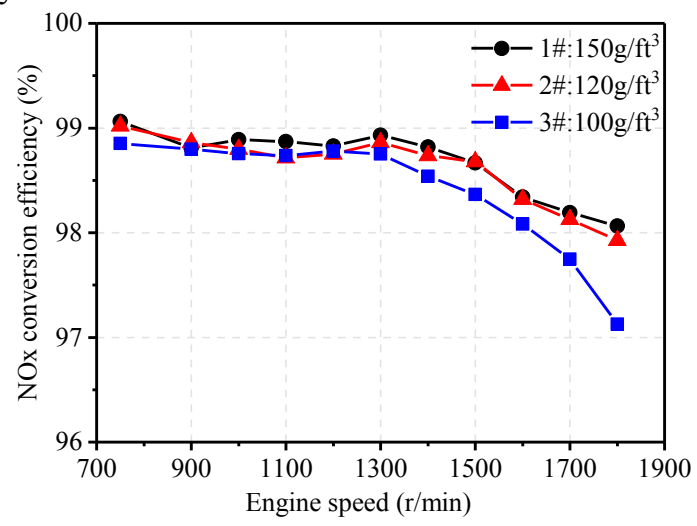

Fig. 10. Effect of noble metal loading on NOx conversion efficiency.

Fig. 11 illustrates the effect of noble metal loading on the THC conversion efficiency of TWCs at $75 \%$ engine load from $750 \mathrm{r} / \mathrm{min}$ to $1800 \mathrm{r} / \mathrm{min}$. At low engine speeds, the THC conversion efficiencies of all three TWCs were high but eventually decreased with the increase of engine speed due to higher THC concentration and exhaust flow velocity. Overall, TWCs with noble metal loading of $150 \mathrm{~g} / \mathrm{ft}^{3}$ and $120 \mathrm{~g} / \mathrm{ft}^{3}$ showed little effect on THC conversion efficiency at all engine speed ranges, but TWCs with noble metal loading of 100 showed an obvious negative effect on THC conversion. A proper increase in noble metal loading can enhance the conversion efficiency of both NOx and THC, but increasing the loading means increasing the cost of the after-treatment system, so it is necessary to comprehensively consider the catalytic performance and economy.

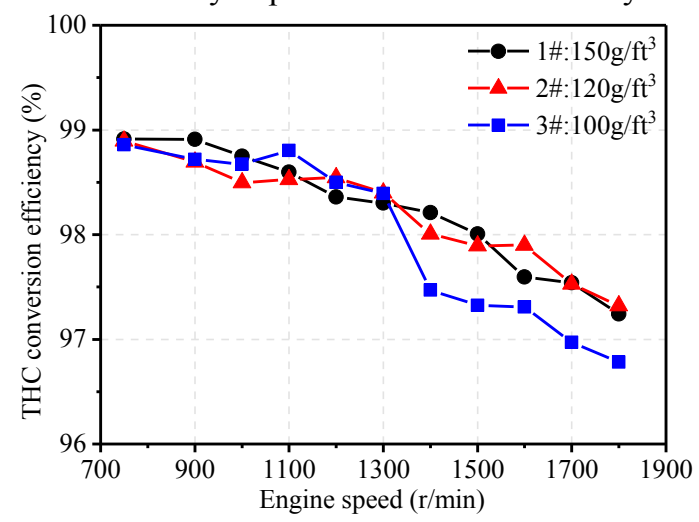

Fig. 11. Effect of noble metal loading on THC conversion efficiency.

\subsubsection{Effect of noble metal ratio}

To access the effect of noble metal ratio on the performance of TWCs, emission tests were conducted on the natural gas engine matching with four different TWCs. The noble metal ratio (Pt:Pd:Rh) was 45:100:15 for 1\# TWC (baseline), 30:100:10 for 4\# TWC (less Pt), 55:85:10 for 5\# TWC (more Pt), and 0:140:10 for 6\# TWC (Pd-Rh), as mentioned in Table 3 . 
Fig. 12 shows the effect of noble metal ratio on the NOx conversion efficiency of TWCs at $75 \%$ engine load from $750 \mathrm{r} / \mathrm{min}$ to $1800 \mathrm{r} / \mathrm{min}$. At high engine speeds, $5 \# \mathrm{TWC}$ and $6 \#$ TWC showed obvious drops in NOx conversion efficiency, and the NOx conversion efficiency of 4\# TWC also showed a certain degree of decline. This is because rhodium is mainly used for the catalytic reduction of NOx [22], so the content of Rh can greatly affect the conversion of NOx. 1\# TWC had a higher Rh content and showed a better NOx conversion effect, whereas 5\# TWC and 6\# TWC had lower Rh contents and hence poorer NOx conversion efficiency at high engine speeds.

Fig. 13 illustrates the effect of noble metal ratio on the NOx conversion efficiency of TWCs at $75 \%$ engine load from $750 \mathrm{r} / \mathrm{min}$ to $1800 \mathrm{r} / \mathrm{min}$. Similar to NOx conversion, noble metal ratio showed little effect on THC conversion at low engine speed as the conversion ratio remained at more than $98 \%$. However, when engine speed was high, it can be seen from the curve that the Pt content in the catalyst had a significant effect on THC emissions. LowPt TWC (4\#) and Pd-Rh TWC (6\#) both had a low conversion efficiency of THC. The 6\# catalyst had no Pt and the main part of catalyst was Pd, which is more sensitive to AFR due to the narrow efficient working window, and thus a more obvious drop of THC conversion can be observed at high engine load. In contrast, the high-Pt catalyst (5\#) improved the catalytic conversion efficiency of THC in the high-speed section, maintaining a higher efficiency at all speeds.

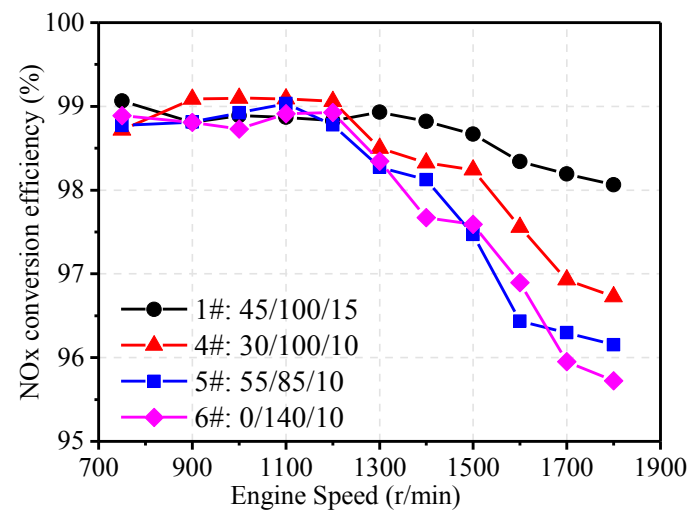

Fig. 12. Effect of noble metals ratio on NOx conversion efficiency.

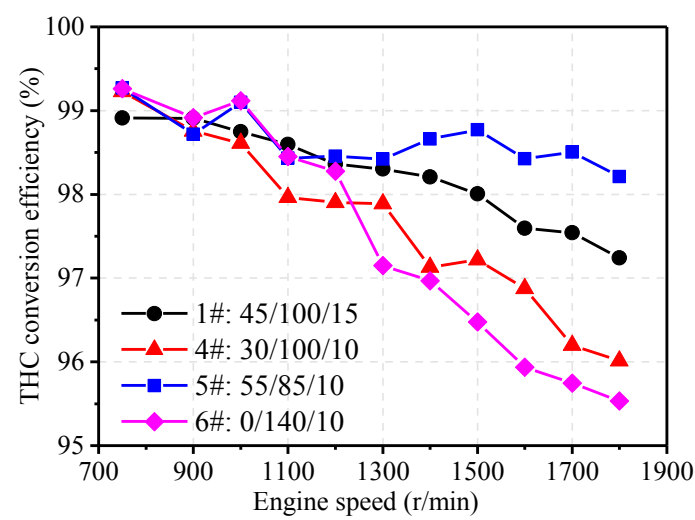

Fig. 13. Effect of noble metals ratio on THC conversion efficiency. 


\subsubsection{Effect of pore density of carrier}

To access the effect of carrier pore density on the performance of TWCs, emission tests were conducted on the natural gas engine matching with two different TWCs. The pore density of the carrier was 400 channels per square inch (cpsi) for $1 \#$ TWC and $600 \mathrm{cpsi}$ for 7\#TWC. A comparison of carrier parameters is displayed in Table 6.

Table 6. Comparison of carrier parameters of $1 \#$ and 7\#TWC.

\begin{tabular}{|l|c|c|}
\hline \multirow{2}{*}{ Parameters of carrier } & \multicolumn{2}{|c|}{ Pore density of carrier } \\
\cline { 2 - 3 } & $\mathbf{4 0 0} \mathbf{~ c p s i}$ & $\mathbf{6 0 0} \mathbf{~ c p s i}$ \\
\hline Pore area $\left(\mathrm{mm}^{2}\right)$ & 1.36 & 0.92 \\
\hline $\begin{array}{l}\text { Geometric surface area } \\
\text { per unit volume }\left(\mathrm{m}^{2} / \mathrm{m}^{3}\right)\end{array}$ & 2897 & 3575 \\
\hline Porosity $(\%)$ & $84.6 \%$ & $85.9 \%$ \\
\hline Pore wall thickness $(\mathrm{mm})$ & 0.102 & 0.076 \\
\hline Hydraulic diameter $(\mathrm{mm})$ & 1.17 & 0.96 \\
\hline
\end{tabular}

Compared with the 400 cpsi carrier, the 600 cpsi carrier had a higher geometric surface area and porosity but a lower pore wall thickness and hydraulic diameter. The increase of the geometric surface area of the carrier can increase the contact area between the reaction gas and catalyst, thus enhancing the catalytic reaction rate. The smaller the hydraulic diameter, the higher the convective mass transfer coefficient, which promotes the heterogeneous catalytic reaction to some extent. To study the effect of carrier pore density on the catalytic reaction in the carrier, a TWC numerical model was established using the simulation method mentioned in Section 2.3. Based on the model, the catalyst reaction rate and gas temperature of two TWCs with different pore densities were simulated. After long-term use of the catalyst, the catalyst will age, and catalytic performance will be reduced. In order to simulate aging, catalyst relative activity $\alpha$ was introduced to characterize the degree of catalyst deactivation. The definition of relative activity is shown in Eq. (11) [29], and $\alpha$ was taken as 0.1 in simulation.

$$
\alpha=\frac{\gamma_{A}}{\gamma_{0}}
$$

where $\gamma_{A}$ is the actual reaction rate of reactant $\mathrm{A}$ on catalyst and $\gamma_{0}$ is the reaction rate of reactant $A$ on fresh catalyst.

Fig. 14 shows the change of the molar concentration of $\mathrm{O}_{2}$ along the axial position of the carrier before and after aging. As shown in the figure, the catalytic oxidation rate in the TWC with 600 cpsi was faster, as the molar concentration of $\mathrm{O}_{2}$ decreased by about $99 \%$ at 0.05 $\mathrm{m}$, whereas in the TWC with $400 \mathrm{cpsi}$ the molar concentration of $\mathrm{O}_{2}$ decreased by about $99 \%$ at $0.069 \mathrm{~m}$. Compared with the fresh catalysts, the rate of decrease of $\mathrm{O}_{2}$ concentration was significantly slower in the aged catalysts. At the end of the simulation, both aged catalysts still contained much $\mathrm{O}_{2}$, although the concentration of the $600 \mathrm{cpsi}$ TWC was lower. 


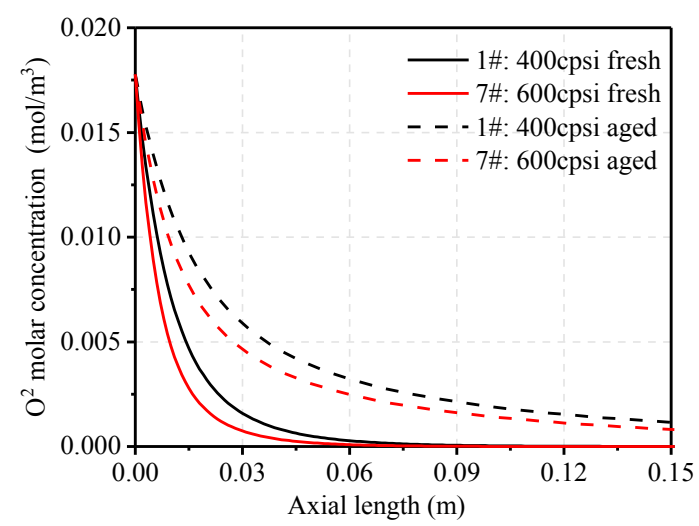

Fig. 14. Effect of pore density on oxidation reaction rate.

Fig. 15 shows the change of gas temperature along the axial position of the carrier before and after aging. Due to the larger geometric surface area of the carrier, the contact area between the reaction gas and catalyst increased in 7\#TWC and led to a higher catalytic reaction rate. Thus, the catalytic reaction was more concentrated on the front side of the carrier and caused a rapid increase of gas temperature in the front of the carrier. As can be seen in the figure, the gas temperature increase rate in 7\#TWC was much higher than that in $1 \# T W C$, and the increase of gas temperature within a certain range helped the catalytic reaction proceed. Compared with fresh catalysts, the increase rates in the front of the carrier were much lower after aging. The middle and rear part of the carrier still contained much $\mathrm{O}_{2}$; thus, the temperature tended to increase monotonically.

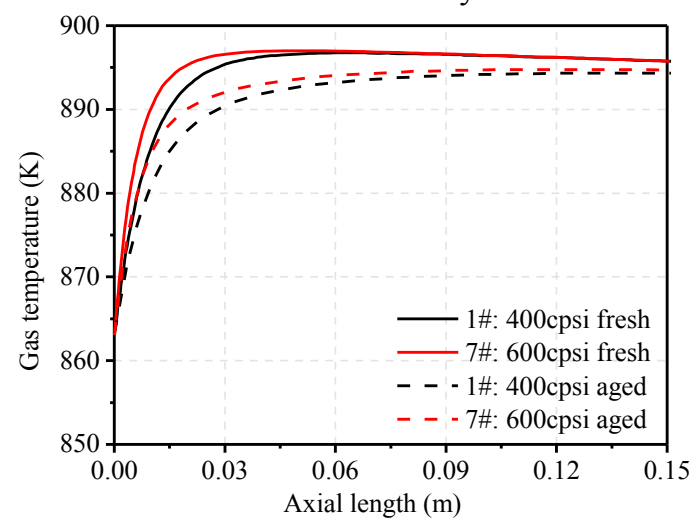

Fig. 15. Effect of pore density on gas temperature distribution.

Fig. 16 and Fig. 17 illustrate the effect of pore density on the NOx and THC conversion efficiency of TWCs at $75 \%$ engine load from $750 \mathrm{r} / \mathrm{min}$ to $1800 \mathrm{r} / \mathrm{min}$. As shown in Fig. 16, TWC with higher pore density showed little effect on NOx conversion efficiency at low and medium speed conditions, and a slightly increased effect at high engine speeds. Similar to NOx, the THC conversion efficiency of the $600 \mathrm{cpsi}$ TWC was much higher than that of the $400 \mathrm{cpsi}$ TWC, and its efficiency was increased by $0.68 \%$ at $1800 \mathrm{r} / \mathrm{min}$. Overall, the increase of the pore density of the carrier can improve the catalytic performance of TWCs, especially at high engine speeds. In addition, the conversion efficiency of catalysts with higher pore density after aging was much higher than that of catalysts with low pore density. Increasing pore density also increases the cost of the after-treatment system, and the improvement of 
catalytic performance is quite limited at low and medium speeds, and thus should be further discussed in engineering application.

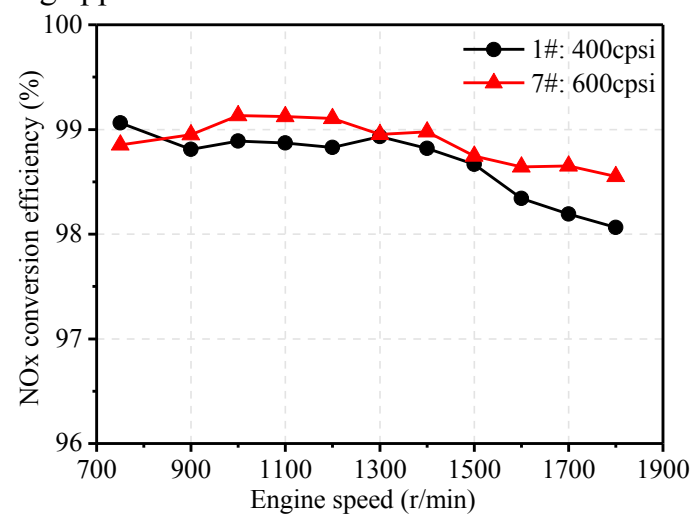

Fig. 16. Effect of pore density on NOx conversion efficiency.

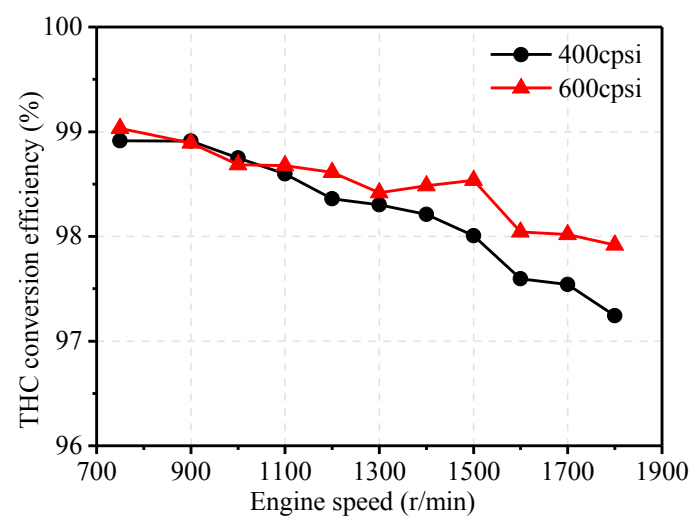

Fig. 17. Effect of pore density on THC conversion efficiency.

\section{Conclusions}

In order to study the effect of TWC parameters on the after-treatment performance of natural gas engines, bench tests and numerical simulations were conducted in this study. The effects of AFR, engine speed, and engine load on the inlet gas component of TWC, and the effects of noble metal loading, noble metal ratio, and carrier pore density on the conversion efficiency of NOx and THC were discussed. The main conclusions from the study are summarized as follows:

(1) AFR can significantly affect the raw emissions of NOx and THC, and better emission conversion efficiency of TWC can be reached when AFR is controlled between 0.995 to 1. Increasing engine speed leads to higher NOx emissions, exhaust temperature and flow velocity. Compared with engine speed, engine load has a relatively small effect on exhaust temperature but greatly affects the flow velocity as well as NOx and THC emissions.

(2) Increasing noble metal loading can improve the catalytic performance, especially at high engine speeds. Increasing the content of $\mathrm{Pt}$ in the catalyst can improve the THC conversion efficiency. For low $\mathrm{Pt}$ and $\mathrm{Pd}-\mathrm{Rh}$ catalysts, the THC conversion effect is significantly deteriorated. The content of $\mathrm{Rh}$ affects the NOx conversion. When $\mathrm{Rh}$ 
content is reduced, the catalytic conversion efficiency of NOx at high speeds is significantly reduced.

(3) Higher pore density of the carrier enhances the catalytic reaction rate and gas temperature in the carrier. Conversion efficiency is also improved at high engine speeds. After aging, TWC with high carrier pore density can still maintain high catalytic conversion efficiency.

The authors would like to acknowledge the financially support by National Key R\&D Program of China (2017YFE0102800)

\section{References}

1. Duan X, Li Y, Liu J, Guo G, Fu J, Zhang Q, et al. Experimental study the effects of various compression ratios and spark timing on performance and emission of a leanburn heavy-duty spark ignition engine fueled with methane gas and hydrogen blends. Energy,2019;169:558-71.

2. Fagundez J, Golke D, Martins M, Salau N. An investigation on performance and combustion characteristics of pure n-butanol and a blend of n-butanol/ethanol as fuels in a spark ignition engine. Energy 2019,176: 521-30.

3. Ibrahim A, Bari S. An experimental investigation on the use of EGR in a supercharged natural gas SI engine. Fuel, 2010, 89(7): 1721-1730.

4. Hajbabaei M, Karavalakis G, Johnson K, et al. Impact of Natural Gas Fuel Composition on Criteria, Toxic, and Particle Emissions from Transit Buses Equipped with Lean Burn and Stoichiometric Engines, Energy, 2013,62(2): 425-434.

5. Ou X, Zhang X . Life-Cycle Analyses of Energy Consumption and GHG Emissions of Natural Gas-Based Alternative Vehicle Fuels in China. Journal of Energy, 2013, 2013:18.

6. Li Y, Wang P, Wang S, et al. Quantitative investigation of the effects of CR, EGR and spark timing strategies on performance, combustion and NOx emissions characteristics of a heavy-duty natural gas engine fueled with 99\% methane content. Fuel, 2019, 255

7. Einewall P, Tunestal P, Johansson B. Lean burn natural gas operation vs. stoichiometric operation with EGR and a three-way catalyst. SAE Technical Paper, 2005.

8. Sen A K , Litak G, Yao B F , et al. Analysis of pressure fluctuations in a natural gas engine under lean burn conditions. Applied Thermal Engineering, 2010, 30(6-7):776779.

9. Li M, Zhang Q, Li G. Emission characteristics of a natural gas engine operating in leanbum and stoichiometric modes . Journal of Energy Engineering, 2016, 142(3): 04015039.

10. Qiang Z, Xu Z, Li M, et al. Combustion and emissions of a Euro VI heavy-duty natural gas engine using EGR and TWC. Journal of Natural Gas Science \& Engineering, 2016, 28(7):660-671.

11. Zheng J, Wang J, Zhao Z, et al. Effect of equivalence ratio on combustion and emissions of a dual-fuel natural gas engine ignited with diesel. Applied Thermal Engineering, 2019, 146: $738-751$.

12. Gandhi H S , Graham G W , Mccabe R W . Automotive Exhaust Catalysis. Journal of Catalysis, 2003, 216(1-2):433-442.

13. Marc Salaün, Kouakou A, Stéphanie Da Costa, et al. Synthetic gas bench study of a natural gas vehicle commercial catalyst in monolithic form: On the effect of gas composition. Applied catalysis b environmental, 2009, 88(3-4):386-397. 
14. Xi Y, Ottinger N A, Liu Z G. The Dynamics of Methane and $\mathrm{NO}_{\mathrm{x}}$ Removal by a ThreeWay Catalyst. SAE International Journal of Engines, 2018, 11(6): 1331-1342.

15. Lin Y, Research on Combustion and Emission Characteristics of a Natural Gas Engine. Tianjin University, China, 2018.

16. Karavalakis G, Hajbabaei M, Jiang Y, et al. Regulated, greenhouse gas, and particulate emissions from lean-burn and stoichiometric natural gas heavy-duty vehicles on different fuel compositions. Fuel, 2016, 175:146-156.

17. Tabata T, Baba K, Kawshima H, et al. NOx reduction catalysts systems for natural gasfuelled engine cogeneration systems. Catalysis Science \& Technology, 1995, 92:453456.

18. Kalam M A, Masjuki H H, Redzuan M, et al. Development and test of a new catalytic converter for natural gas fueled engine. Sadhana, 2009, 34(3):467-481.

19. Liotta L F, Carlo G D, Pantaleo G, et al. Co3O4/CeO2 composite oxides for methane emissions abatement: Relationship between $\mathrm{Co} 3 \mathrm{O} 4-\mathrm{CeO} 2$ interaction and catalytic activity. Applied Catalysis B Environmental, 2006, 66(3):217-227.

20. Li Z, Zhu L, Li J, et al. Effect of A/F ratio fluctuation on light-off performance of methane of TWC for CNG engine. Journal of Jilin University, 2019 (1): 11.

21. Huo C, Zheng B, Wang F, et al. Influence of Noble Metal Ratio on Performance of Three-Way Catalyst for Gas Engine.Internal Combustion Engine \& Powerplant,2019,36(05):20-24

22. Zhang Q, Li N, Li G. Three-waycatalystforanatural-gasengine. Journal of Shandong University, 2010, 40(4).

23. Xi Y, Ottinger N, Liu Z G. Development of a Lab Reactor System for the Evaluation of Aftertreatment Catalysts for Stoichiometric Natural Gas Engines. SAE Technical Paper, 2017.

24. Takayuki Sakai, Byung, Ryuji Osuga, et al. Purification Characteristics of Catalytic Converters for Natural Gas Fueled Automotive Engine. bulletin of the chemical society of japan, 1991, 49(17):169-173.

25. Oh S H , Mitchell P J , Siewert R M . Methane Oxidation Over Alumina-Supported Noble Metal Catalysts with and without Cerium Additives. Cheminform, 1991, 132(2):287-301.

26. Di Maio D, Beatrice C, Fraioli V, et al. Modeling of Three-Way Catalyst Dynamics for a Compressed Natural Gas Engine during Lean-Rich Transitions. Applied Sciences, 2019, 9(21): 4610.

27. Zeng F, Finke J, Olsen D, et al. Modeling of three-way catalytic converter performance with exhaust mixtures from dithering natural gas-fueled engines. Chemical Engineering Journal, 2018, 352: 389-404.

28. Koltsakis G C, Konstantinidis P A, Stamatelos A M. Development and application range of mathematical models for 3-way catalytic converters. Applied Catalysis B: Environmental, 1997, 12(2-3): 161-191.

29. Hu E, Huang Z, Liu B, et al. Experimental investigation on performance and emissions of a spark-ignition engine fueled with natural gas-hydrogen blends combined with EGR. International journal of hydrogen energy, 2009, 34(1): 528-539. 